Revista de Economia Política, vol. 29, $n^{\circ} 3$ (115), pp. 256-273, julho-setembro/2009

\title{
Inovações financeiras e institucionais do sistema de financiamento residencial americano
}

\author{
RAFAEL FAGUNDES CAGNIN*
}

Institutional and financial innovations in the U.S. housing finance system. This article has the gold of summarize the institutional modifications of the US housing finance system between the 60's and the end of the 90's. Those changes narrowed the bonds between this segment of the credit market and the securitized financial markets, encouraging the foundation and diffusion of financial innovations that are in the core of the current financial crises.

Keywords: housing finance; financial innovations; United States

JEL Classification: G1; G21; N22.

\section{INTRODUÇÃO}

A introdução de inovações nos contratos e práticas consiste em um instrumento central no processo de concorrência entre as instituições financeiras, sejam elas bancárias ou não-bancárias. A busca por lucro condiciona estratégias por meio das quais uma instituição procura diferenciar-se das outras, lançando mão de técnicas de marketing, importantes para construir ou reafirmar uma imagem de solidez e experiência, de investimentos em tecnologia e da expertise de seus gestores. A introdução de um novo instrumento financeiro, da sua criação à sua comercialização, acaba por sintetizar essas estratégias de concorrência, permitindo que as instituições financeiras compatibilizem os produtos e serviços ofertados às características daqueles demandados pelo público (Freitas, 1997).

Nas finanças contemporâneas as inovações financeiras ocupam papel importante nas estratégias de ampliação dos ativos das instituições assim como na gestão

\footnotetext{
* Economista, mestre em Teoria Econômica pela Universidade Estadual de Campinas com apoio do $\mathrm{CNPq}$, doutorando em Economia na Université Paris XIII/Nord com apoio do Programa Alßan. E-mail: rfcagnin@gmail.com. O autor agradece pelos comentários e sugestões de Maryse Fahri, Marcos Antonio M. Cintra e dos pareceristas da revista, isentando-os dos erros remanescentes.
} 
de seu passivo. A diversificação dos mecanismos de captação, em que se destaca a prática da securitização, permitiu que bancos e demais instituições pudessem definir o ritmo de crescimento de seu ativo para em seguida compor sua estrutura passiva (Minsky, 1984).

Se no âmbito microeconômico as inovações desempenham a função de instrumento de concorrência e, consequentemente, de obtenção de lucros extraordinários por meio de vantagens competitivas, elas apresentam também desdobramentos sobre o âmbito macroeconômico, o que lhes confere, assim, um caráter dual. Durante o período de expansão da economia, as inovações financeiras atenuam o aumento prócíclico das taxas de juros, possibilitando a ampliação contínua do endividamento (e da fragilidade patrimonial) dos agentes econômicos até o momento de instabilidade em que os fluxos de rendas esperadas mostram-se insuficientes para saldar os compromissos financeiros assumidos anteriormente, devido a um aumento imprevisto das taxas de juros ou à frustração de expectativas. Por ampliarem a complexidade das relações de débito e crédito, os novos instrumentos tornam menos previsível a extensão das crises financeiras elevando o risco sistêmico e dificultando a atuação dos bancos centrais na gestão de liquidez (Minsky, 1984, 1986).

Contudo, as inovações financeiras também estão presentes nas fases de estagnação econômica ou de deflação de dívidas, por meio das quais as instituições credoras buscam reestruturar os compromissos de clientes inadimplentes, atrair aqueles que se encontram em melhor situação patrimonial e gerir a elevação dos riscos de suas carteiras (Freitas, 1997; Cintra \& Cagnin, 2007a).

Assim, devido à concorrência, as instituições financeiras se veem constantemente pressionadas a criar novos instrumentos. $O$ fato de não existir registro de patentes para as inovações financeiras e a facilidade com que podem ser copiadas pelos concorrentes reforçam essa tendência.

As inovações financeiras apresentam uma relação de duplo sentido com o arranjo institucional que, por sua vez, define o ambiente de concorrência dos agentes financeiros. Por um lado, fatores institucionais específicos (leis e normas que compõem o quadro regulatório) de cada sistema financeiro nacional condicionam a capacidade de criação de novos instrumentos, à medida que definem o conjunto de escolhas possíveis que compõem as estratégias concorrenciais dos agentes financeiros (Amable, 2005). Aglietta (1987) chama a atenção, por exemplo, para as características do sistema jurídico na Europa Continental e nos EUA e Grã-Bretanha. Nesses últimos prevalece a common law (tudo que não é proibido é permitido) o que garante aos agentes financeiros maior liberdade para desenvolver novas práticas e instrumentos financeiros do que na maioria dos países europeus, onde predomina a civil law (tudo que não é permitido é proibido).

Por outro lado, as inovações financeiras também permitem a adaptação das condições de financiamento a mudanças econômicas, não apenas cíclicas, mas inclusive aquelas de caráter estrutural. A criação de novos instrumentos pode fazer parte de estratégias que tenham o objetivo de contornar os limites impostos pela regulação, desencadeando um processo de "obsolescência" do arranjo institucional em vigência, incitando um movimento de re-regulação por parte dos órgãos competentes que venha a validar as práticas correntes. Foi um processo dessa natureza que levou à transformação da estrutura do sistema financeiro americano dos anos 
1930 em direção às suas características atuais (Freitas, 1997; Braga e Cintra, 2004; Cintra e Cagnin, 2007a).

As mudanças na conjuntura econômica dos Estados Unidos (EUA) a partir de meados dos anos 1960 (elevação das taxas de juros, aceleração da inflação e baixo crescimento econômico), que refletiam o desgaste do arranjo político-institucional do pós-guerra, aprofundadas na década seguinte, deram origem a um intenso processo de inovação financeira seguido pelo desmantelamento de controles quantitativos (Glass-Steagal Act de 1933 e Securities Exchange Act de 1934), que constituíam, até então, uma das principais características do sistema financeiro americano (Belluzzo e Coutinho, 1996).

Data desse período o processo de "institucionalização da poupança" americana - isto é, o aumento da importância dos investidores institucionais como gestores de riqueza e de crédito em relação às instituições de depósito - e o crescimento dos mercados de títulos de dívida (securities) e de derivativos. A essas tendências, que consistiam numa elevação do nível de concorrência, os grandes bancos americanos reagiram introduzindo outras inovações financeiras (certificados de depósito, repurchase agreement etc.) de maneira a contornar os limites às taxas de juros aos quais estavam sujeitos (Cintra, 1997).

A concorrência entre as instituições bancárias e não-bancárias e a introdução de inovações financeiras, seja nas formas de captação, seja na gestão de riscos e das operações ativas, transformaram o negócio bancário. Os grandes bancos comerciais lideraram o processo de conglomeração entre diferentes instituições que, sob figuras jurídicas distintas, passaram a oferecer serviços de subscrição de títulos e ações, seguros e gestão de riqueza por meio de fundos de investimento e de pensão ${ }^{1}$ (Cintra e Cagnin, 2007a).

A combinação entre aceleração da inflação e a existência de teto para as taxas de juros de empréstimos e dos depósitos a prazo (Regulação Q) criou problemas para a captação de recursos pelas instituições de saving \& loans (S\&L). A introdução de inovações financeiras pelos grandes bancos e investidores institucionais, sobre as quais não incidiam tetos, reduziu a capacidade das S\&L de atrair depósitos, dificultando o refinanciamento de suas posições ativas, que em grande parte eram constituídas por hipotecas de longo prazo.

Aos problemas de liquidez dos anos 1960 e 1970, foram acrescentados novos desafios com o choque de juros realizado por Paul Volcker em 1979 e com a eliminação dos tetos de taxas de juros, por meio do Depository Institutions Deregulation and Monetary Control Act de 1980. Em função do descasamento de prazos entre suas operações ativas e passivas, a elevação das taxas de juros que seguiram à sua liberalização resultou no encarecimento do funding das S\&L ao mesmo tempo em

\footnotetext{
${ }^{1}$ A remoção da proibição sobre a atuação de filiais bancárias ocorreu em 1994 por meio do RiegleNeal Interstate Banking and Branching Efficiency Act, que permitiu a expansão das filiais e dos bancos interestaduais. A partir de 1999, as bank holding companies conseguiram liberalização ainda maior de suas operações, podendo manter em sua estrutura companhias de seguros e bancos de investimento. A redução das restrições legais impostas às instituições financeiras reforçou a tendência de flexibilização do sistema financeiro americano.
} 
que a rentabilidade de seu ativo continuava definida pelos contratos hipotecários de longo prazo a taxas de juros fixas estabelecidos anteriormente.

Como as S\&L consistiam no principal tipo de instituição geradora de hipotecas, a crise dessas instituições significava necessariamente a crise do arranjo de financiamento residencial.

A gestão da crise desse segmento do mercado de crédito foi liderada pelo governo americano e contou com uma profunda reforma institucional, dando origem a um sistema integrado aos mercados securitizados cuja dinâmica permitiu a forte expansão do financiamento residencial americano depois de 2002, acompanhada de inovações financeiras e de acúmulo crescente de riscos (Cagnin, 2007).

Este artigo tem o objetivo de recuperar esse processo de transformações institucionais que ampliaram a capacidade de introdução de inovações financeiras e está organizado em três seções, além desta breve introdução e da conclusão. As principais transformações institucionais do sistema americano de financiamento residencial e sua integração aos mercados securitizados estão expostas na primeira seção. A segunda seção aborda as principais inovações financeiras, tanto nos contratos hipotecários como nas operações de securitização dessas carteiras de crédito, cuja introdução foi permitida por esse novo arranjo institucional. O papel desempenhado por esses novos contratos e práticas está no centro do processo que fez com que a crise do segmento subprime do crédito residencial americano se transformasse em uma crise mais profunda, atingindo diferentes segmentos dos mercados financeiros internacionais. Essa evolução é discutida na terceira seção do artigo, que apresenta também as medidas recentemente adotadas pelo governo americano com o objetivo de restabelecer as condições de crédito e fortalecer a supervisão do sistema de financiamento residencial.

\section{AS TRANSFORMAÇÕES DO SISTEMA DE FINANCIAMENTO RESIDENCIAL}

Após a crise financeira dos anos 1930, as autoridades americanas buscaram fortalecer e expandir o sistema de financiamento residencial, apoiando as instituições de S\&L e o desenvolvimento de mecanismos que permitissem uma melhor gestão dos riscos por meio da criação de um mercado secundário de hipotecas e da concessão de garantias públicas. Foram criadas três instituições: o Federal Home Loan Bank System (FHLBS) em 1933, a Federal Housing Administration (FHA) em 1934 e a Federal National Mortgage Association (FNMA) em 1938.

Enquanto a $\mathrm{FHA}^{2}$ assumia o risco de crédito de novos contratos de financiamento, funcionando como uma seguradora pública, o FHBLS constituía-se numa

\footnotetext{
${ }^{2}$ A Federal Housing Administration assume o risco de crédito associado às hipotecas tomadas pelos credores de mais baixa renda. A elegibilidade da operação está sujeita a um valor máximo por hipoteca, ajustável de acordo com a tendência dos preços médios dos imóveis em cada região.
} 
fonte alternativa de captação às instituições de depósito associadas ${ }^{3}$. O desenvolvimento de um mercado secundário de hipotecas cabia à FNMA, cujas operações estavam restritas à aquisição das hipotecas garantidas pela FHA.

Apesar das medidas implementadas, o mercado secundário de hipotecas manteve-se restrito até a década de 1970, o que significava que as operações das instituições credoras (e inclusive da FNMA) ainda eram acompanhadas por um elevado descasamento de prazos entre suas estruturas ativa e passiva.

Assim, em frente aos desafios postos pelo ambiente macroeconômico, as autoridades públicas continuaram a incentivar a ampliação do mercado secundário de hipotecas, melhorando as condições de obtenção de liquidez por parte das S\&L. Em 1968, o Housing and Urban Development Act introduziu mudanças no funcionamento do mercado secundário mediante a reformulação do papel da Federal National Mortgage Association, que foi dividida em duas instituições. A "nova" FNMA, atualmente conhecida como Fannie Mae, foi privatizada mas conservou seu papel público, tornando-se uma Government-Sponsored Enterprise (GSE). Foi-lhe permitida a emissão de ações em bolsa de valores e a compra de hipotecas convencionais (conventional mortgages, que não são garantidas pela FHA). A expansão do mercado secundário de hipotecas seguradas pela Federal Housing Administration passou então a ser responsabilidade de uma nova instituição, a Government National Mortgage Association, conhecida como Ginnie Mae. Retirou-se, assim, da responsabilidade da Fannie Mae os créditos hipotecários constituintes de política pública de habitação para os segmentos de renda mais baixa, liberando a instituição para promover o fortalecimento do segmento de hipotecas submetido às "leis de mercado" (Colton, 2002).

No ano de 1970, o Congresso americano criou outra GSE, a Federal Home Loan Mortgage Corporation, que mais tarde passou a ser chamada de Freddie Mac. Com essa nova instituição, as autoridades públicas buscaram dar novo incentivo ao mercado de hipotecas convencionais originadas pelas S\&L. A Freddie Mac passou a ser responsável pela emissão de títulos referenciados a contratos de crédito hipotecário, as mortgage-backed securities (MBS), conhecidos como participation certificates.

Dessa maneira, a partir do início da década de 1970, estava criado o embrião do atual mercado secundário de hipotecas, baseado em MBS. Deve ser ressaltado, contudo, que a Fannie Mae ainda não realizava operações de securitização; sua função estava restrita a adquirir e manter em portfólio hipotecas convencionais. Por esse motivo, as causas que levaram à crise das S\&L do início dos anos 1980 também afetaram a solidez da Fannie Mae (Colton, 2002; HUD, 2006).

No sentido de promover um diagnóstico a respeito da crise das S\&L e seu impacto sobre o sistema de financiamento residencial, foi criada, em 1982, a President's Commission on Housing. O relatório da comissão reconhecia a neces-

\footnotetext{
${ }^{3}$ O Federal Housing Loan Bank System é formado por 12 bancos. Cada um deles funciona como um "banco central" para as instituições associadas ao sistema, provendo a liquidez necessária para o funcionamento do mercado primário de hipotecas.
} 
sidade de criar um sistema em que houvesse maior flexibilidade, de maneira a permitir melhor gestão de riscos. A estratégia fundava-se no desenvolvimento do mercado secundário de hipotecas securitizadas (MBS). Partia-se do princípio de que esse mercado estaria subdesenvolvido diante da evolução dos mercados de títulos de dívida corporativa. As desvantagens provinham de diferentes frentes: legal, regulamentar e tributária, especialmente para as hipotecas sem seguro público.

Nessa mesma direção, em 1981, já havia sido permitida a securitização de hipotecas convencionais pela Fannie Mae, como resposta aos seus desequilíbrios patrimoniais. As recomendações da President's Commission on Housing foram incorporadas no Secondary Mortgage Market Enhancement Act (SMMEA) de 1984. Entre elas, estavam a remoção de limites impostos por lei federal à aquisição de MBS por instituições de depósito, ficando a cargo do órgão regulador a definição dos tetos, e incentivos ao desenvolvimento de mercados futuros de MBS. Ademais, as MBS passariam a receber classificação de high-grade, podendo, assim, ser compradas por fundos de pensão e seguradoras como se fossem títulos emitidos ou garantidos pelo governo federal.

No que diz respeito às condições de concorrência entre as Government-Sponsored Enterprises e outras instituições privadas securitizadoras, o SMMEA determinou limites para o valor das hipotecas a serem compradas pela Fannie Mae e pela Freddie Mac, ajustados periodicamente de acordo com o preço médio das residências. As hipotecas abaixo do valor-limite passaram a ser chamadas de conforming mortgage; as que ultrapassavam o limite ficaram conhecidas como hipotecas jumbo, ou nonconforming mortgage.

A implementação dessas medidas levou à ampliação da liquidez dos títulos no mercado secundário de hipotecas, estreitando as relações entre os mercados de capitais e o mercado de hipotecas. Assim, grandes bancos comerciais, como o Bank of America, também se tornaram importantes emissores de MBS, especialmente a partir de meados dos anos 1980. Um outro aspecto desse processo de aprofundamento do mercado de MBS foi o aumento da diversificação dos tipos de securities relacionadas a hipotecas.

O interesse dos grandes bancos privados no mercado de crédito imobiliário fazia parte das estratégias de expansão das carteiras dos créditos colateralizados voltados a pessoas físicas e a médias e pequenas empresas ${ }^{4}$. Por um lado, a exigência de colateral permitia a melhor gestão dos impactos sobre o balanço patrimonial do banco em caso de ocorrência de default. Por outro lado, as atividades de securitização de hipotecas e os serviços associados ao recolhimento e transferência dos pagamentos do tomador do empréstimo ao investidor proprietário das securities transformaram-se em fontes de receitas por meio de tarifas e comissões (Goodhart e Hofmann, 2007; Bhatia, 2007).

Em 1970, as instituições de S\&L correspondiam por 47,6\% da contratação

\footnotetext{
${ }^{4}$ Os grandes bancos americanos, como Citibank, Bank of America, J.P. Morgan-Chase e Wachovia, aparecem como os grandes players no financiamento residencial, como geradores de hipotecas, servicers e securitizadores (ver http://www.nationalmortgagenews.com).
} 
de empréstimos hipotecários. Em 2001, sua participação chegou a 20,7\% (ver Gráfico 1). O espaço deixado por essas instituições, obrigadas a retrair sua oferta de crédito em função dos desequilíbrios patrimoniais aprofundados a partir da segunda metade dos anos 1970 e pelas restrições impostas pelo Financial Institutions Reform, Recovery and Enforcement Act (FIRREA), de 1989, foi ocupado progressivamente por instituições bancárias especializadas na concessão de crédito hipotecário (mortgage banks) e pelos bancos comerciais.

Com relação aos estoques de crédito hipotecário mantidos em balanço pelos diferentes agentes, houve crescimento da participação das instituições federais e das GSE, em contraste com a queda da participação das instituições de poupança. Essa tendência refletiu a importância do mercado secundário nas operações hipotecárias. As instituições credoras no mercado primário passaram a se desfazer de suas carteiras de crédito hipotecário no mercado secundário. As GSE (Fannie Mae e Freddie Mac), além de emitirem securities baseadas nesses créditos, também ampliaram o volume de hipotecas e de MBS retido em balanço. Em 1970, as instituições federais e GSE possuíam $8,1 \%$ do estoque total de hipotecas, contra uma participação de $43,9 \%$ das instituições de poupança. A relação se inverteu na última década, quando a participação das primeiras atingiu 42,9\% em 2003 e a das últimas, 9,5\%.

Gráfico 1: Geração de hipotecas - participação por tipo de credor - 1970 a 2000

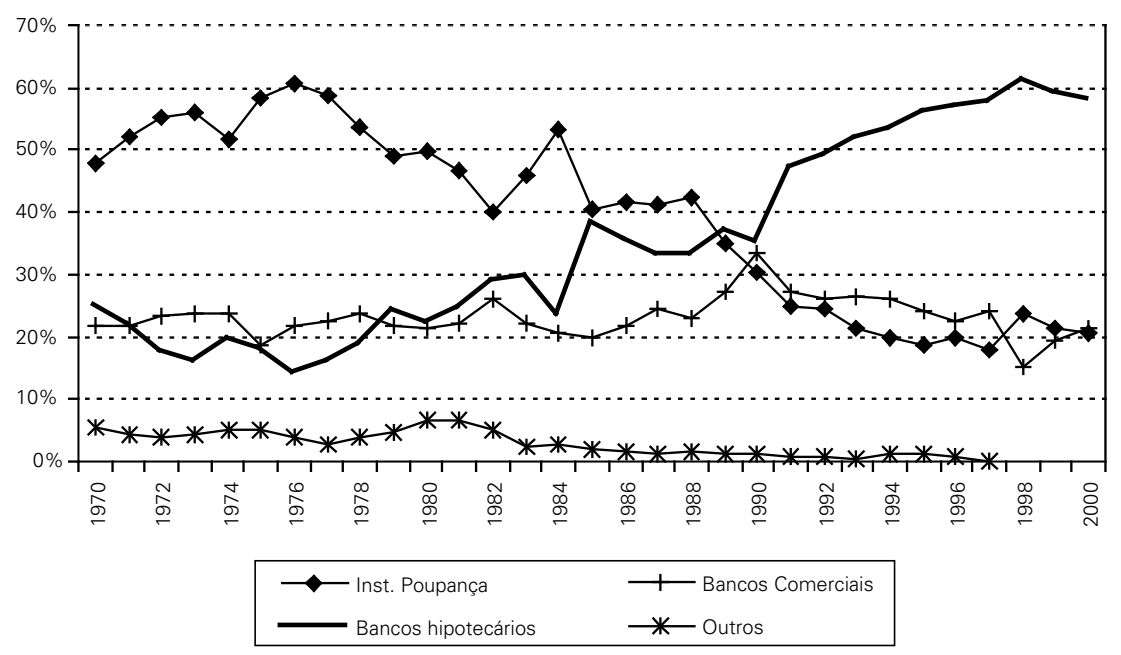

Fonte: U.S. Department of Housing and Urban Development e Fannie Mae, apud Colton (2002).

Notas: Os dados referem-se às single mortgages.

Após 1985 existe mudança de metodologia no tratamento dos dados do HUD, não sendo recomendável, assim, a comparação com dados anteriores.

Entre 1970 e 1977 os dados são provenientes do HUD, entre 1998 e 2000, refere-se a estimativas realizadas pela Fannie Mae, a partir de dados do Home Mortgage Disclosure Act (HMDA), que cobre cerca de $75 \%$ do mercado hipotecário para single family.

Ficavam retidos em balanço, então, apenas os créditos cujos valores ultrapassassem o teto estabelecido para a compra pelas GSE, ou seja, os nonconforming 
loans (jumbo), ou, então, aqueles contratos cuja avaliação de risco impunha um deságio muito grande para serem adquiridos. Entretanto, nos últimos 10 anos o crescimento da participação de emissores privados desse tipo de título (ver Gráfico 2) ampliou a concorrência nesse mercado, colaborando para a introdução de inovações financeiras e facilitando a securitização de créditos jumbo e de alto risco. Diante da conjuntura de baixas taxas de juros a partir de 2001, a busca por rentabilidade intensificou essa tendência e criou a demanda pelos novos instrumentos.

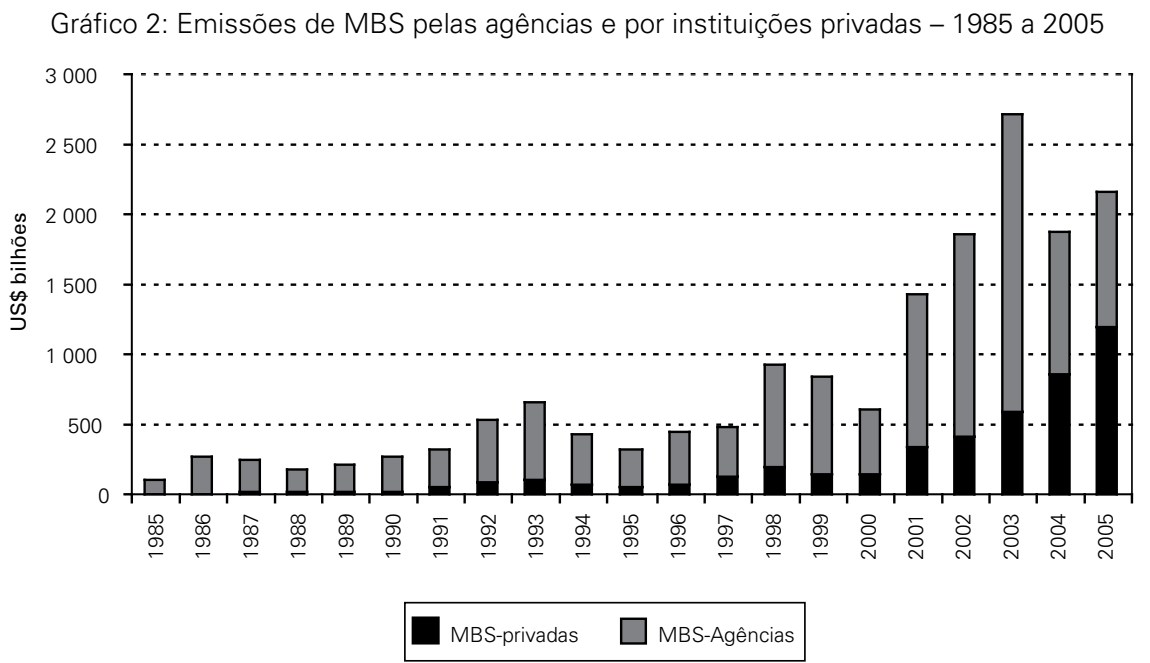

Fonte: Ginnie Mae, Freddie Mac, Fannie Mae e Inside MBS\&ABS. apud Vallee (2006).

\section{INOVAÇÕES FINANCEIRAS RECENTES}

A partir do final dos anos 1970, pari passu ao movimento de formação do atual sistema de financiamento residencial, por meio de alterações nos marcos regulatórios e da criação de instituições, outro processo tomava início: a diversificação dos tipos de contratos hipotecários, no mercado primário, e de securities relacionadas a eles, no mercado secundário. $\mathrm{Na}$ verdade, as inovações nos contratos hipotecários faziam parte de um movimento mais amplo de inovações financeiras, iniciado nos anos 1970 e aprofundado a partir da década seguinte. A incompatibilidade da regulação do sistema financeiro à nova conjuntura macroeconômica, em que estiveram presentes níveis cada vez maiores de inflação e de taxas de juros, deu início a esse processo. A própria lógica da concorrência, por meio das inovações financeiras, foram quebrando as amarras regulatórias (Freitas, 1997).

No caso específico do financiamento residencial, a introdução de inovações foi estimulada inicialmente pela iniciativa pública, por meio das instituições do mercado secundário (Fannie Mae, Freddie Mac e Ginnie Mae) e por alterações na regulamentação. A necessidade de incentivo público na criação de novos contratos 
pode ser explicada por dois aspectos. Em primeiro lugar, as instituições de S\&L, principais responsáveis pela geração de hipotecas, estavam enfrentando dificuldades crescentes, agravadas a partir da década de 1980, e não se mostraram capazes de sustentar o funcionamento do sistema de financiamento residencial sozinhas. Em outras palavras, a manutenção das operações hipotecárias ia de encontro com a necessidade de casamento de prazo entre seus ativos, de longo prazo, e sua estrutura de funding, de curto prazo; ademais, inovações financeiras significavam a não elegibilidade dos créditos às garantias públicas e à compra pelas GSE. Em segundo lugar, havia claro interesse público em manter funcionando esse sistema de crédito, dada a importância da ampliação do acesso à propriedade residencial na sociedade americana (American dream) e a contribuição da construção civil na geração de emprego e renda.

Dessa forma, na tentativa de reduzir os descasamentos de taxas de juros das S\&L e a contração do crédito no financiamento residencial, o governo americano decidiu ampliar o mercado secundário de hipotecas a partir da década de 1980, quando, inclusive, a Fannie Mae passou a ter permissão para securitizar contratos hipotecários. É também desse período o Alternative Mortgage Transaction Parity Act (1982) que autorizou as S\&L a contratar hipotecas a taxas de juros flexíveis, as adjustable rate mortgages (ARM).

Conforme se aprofundava o mercado secundário de hipotecas, um conjunto maior de agentes privados se interessava em atuar com financiamento residencial. A crescente desregulamentação financeira e a intensificação da concorrência têm levado, desde então, a uma maior proliferação de contratos "não-tradicionais".

A introdução dos contratos de ARM não foi de grande efetividade para a recuperação das S\&L, dado que o problema de liquidez já havia se instaurado. Contudo, a participação desse tipo de contrato se ampliou, especialmente no ambiente de taxas de juros estáveis e baixas, a partir de 2003 (HUD, 2006; Bernanke, 2007). Outras inovações seguiram as ARM sem, contudo, nunca atingir participação expressiva. Foram elas:

- Price Level Adjusted Mortgage, cujo serviço da dívida está atrelado a um índice de inflação previamente acordado.

- Shared Appreciation Mortgage, contrato em que a instituição credora aceita receber uma taxa de juros (geralmente fixa) mais baixa que contratos semelhantes de mesma maturidade em troca do direito de se apropriar de uma parcela da valorização do imóvel financiado. Assim, no prazo estabelecido no contrato, o tomador do empréstimo deverá pagar a porcentagem acordada à instituição financeira (vendendo o imóvel ou obtendo outro tipo de empréstimo) ou, então, refinanciar sua hipoteca de maneira a incluir esse montante junto ao principal a ser pago.

O avanço da tecnologia e de diferentes instrumentos de mitigação de riscos ao longo dos anos 1990, juntamente com a profundidade do mercado secundário de hipotecas e a tendência à valorização dos imóveis permitiram uma nova fase de inovações dos contratos. Com a deflação de ativos das bolsas de valores e a manutenção de baixos patamares de taxas de juros a partir de 2001, as instituições financeiras intensificaram a busca por ativos de maior rentabilidade. O desenvolvi- 
mento de novos instrumentos no mercado primário de hipotecas permitiu, de um lado, que as famílias americanas ampliassem sua capacidade de endividamento dando como garantia seus imóveis em tendência de valorização e, por outro, satisfazia o desejo de crescimento das operações ativas das instituições financeiras.

Os novos contratos seguiram na direção de permitir que os tomadores realizassem pagamentos menores no período inicial de existência da hipoteca (balloon mortgage), possibilitando, assim, uma menor relação entre o serviço da dívida e a renda pessoal. Dessa forma, foi ampliado o universo de possíveis tomadores de crédito hipotecário, com importantes consequências sobre os riscos potenciais presentes no sistema de financiamento residencial. Entre os principais contratos desenvolvidos, destacaram-se:

- Interest-Only Mortgage (IO), por meio do qual o tomador pode pagar apenas os juros sobre o valor do empréstimo durante um período de tempo predeterminado. A cada vencimento mensal o tomador tem o direito de decidir se paga apenas os juros ou juros acrescidos da amortização do principal.

- Negative Amortization Mortgage (Neg-Am), cujo tomador tem direito (durante um período definido por contrato) a fazer escolha entre três opções: pagar somente juros ou juros acrescidos da amortização ou realizar um pagamento "mínimo", estabelecido em contrato, cujo valor é menor que o pagamento dos juros. A diferença entre o mínimo e o montante de juros daquele período é incorporada no principal do empréstimo (amortização negativa). Esse tipo de contrato garante pagamentos reduzidos no início, mas que podem crescer expressivamente passado o período de validade da opção. Dependendo das condições do contrato, os pagamentos mensais podem se elevar em mais de $40 \%$.

- Hybrid-ARM, semelhante às demais, busca reduzir os pagamentos durante os primeiros anos de existência da hipoteca. Nesse contrato, durante o período inicial, geralmente de 2 a 5 anos, o tomador paga taxas fixas de juros, consistindo na verdade numa FRM. Após essa fase, as taxas de juros tornam-se flexíveis, em geral ajustadas semestralmente de acordo com a Libor (London Interbank Offer Rate); isto é, passa a consistir numa ARM. Vale lembrar que desde o início os pagamentos mensais incluem as parcelas referentes à amortização.

- Hybrid IO-ARM, como no caso da hipoteca hybrid-ARM, esse contrato associa taxas fixas e flexíveis, mas agora oferece a possibilidade de o tomador realizar pagamentos referentes apenas ao montante de juros, por um período predeterminado.

Outra prática que se popularizou no mercado primário é a segunda hipoteca, conhecida como piggyback, emitida simultaneamente à hipoteca principal. A existência desse contrato pode isentar o tomador de realizar qualquer sinal ou entrada no momento de contratação da hipoteca. Contratos tradicionais geralmente exigem um sinal de $20 \%$, ou seja, a hipoteca cobre apenas $80 \%$ do valor do imóvel. Caso queira uma relação maior entre o valor da hipoteca e do imóvel (loan-to-value LTV), o tomador deve, na maioria dos casos, fazer um seguro junto a uma instituição privada. O grande incentivo para se tomar uma segunda hipoteca sobre o valor do imóvel não coberto pela primeira é fiscal. Os gastos com pagamento de juros 
sobre hipotecas são dedutíveis do imposto de renda, enquanto os gastos com seguro não são.

Uma maneira comum de se fazer uma piggyback é por meio do Home Equity Loan (HEL), que consiste numa linha de crédito com fim específico (geralmente para melhorias no imóvel ou para complementar sua compra), tendo como colateral o valor do imóvel ainda não utilizado como garantia de outra hipoteca. O limite máximo do empréstimo é definido a partir da análise de crédito do tomador e da existência de hipotecas sobre o imóvel a ser tomado como colateral. Sobre os HELs incidem geralmente taxas de juros fixas. Outra maneira de se adquirir uma piggyback é realizando um Home Equity Lines of Credit (HELOC), que é um tipo de crédito pré-aprovado que toma um imóvel como garantia, de maneira semelhante ao HEL. Entretanto, o HELOC não necessita da definição de um fim específico para o uso dos recursos emprestados, que tanto podem ser usados para complementar uma primeira hipoteca como para o consumo em geral. Home Equity Loan e Home Equity Lines of Credit consistem nos dois tipos de Home Equity Lending.

O crescimento da participação de contratos não tradicionais, em que geralmente estavam presentes balloon payments, assim como a maior possibilidade de ampliar a relação loan-to-value, marcaram o desenvolvimento do sistema de financiamento residencial nos EUA após 2001, expandindo os riscos implícitos das operações no mercado primário ${ }^{5}$. Tanto as instituições credoras como os tomadores esperavam, ao contratar hipotecas com essas características, que a tendência de valorização do imóvel se mantivesse ou que as taxas de juros futuras fossem reduzidas, de maneira que pudessem refinanciar as hipotecas em condições favoráveis.

Os contratos no mercado secundário também passaram por processos de sofisticação desde a primeira emissão de uma MBS pela Ginnie Mae no início dos anos 1970. O pass-through ou single class MBS emitida por essa agência consiste na simples transferência do fluxo de pagamento realizado pelo tomador da hipoteca ao detentor do título, depois de serem descontadas as taxas e comissões dos agentes financeiros envolvidos na operação.

A partir da década seguinte, Fannie Mae e Freddie Mac passaram a emitir multiple-class MBS, também conhecida como Collateralized Mortgage Obligation (CMO). A partir de um conjunto de MBS lastreado por hipotecas de diferentes maturidades e níveis de risco, as GSEs emitem diversas classes de securities (tranches) que são hierarquizadas de acordo com a prioridade de recebimento de fluxo de pagamento e da absorção de perdas provenientes da ocorrência de default nas hipotecas utilizadas como colateral. Geralmente existem três classes de securities: sênior, mezzanine e júnior. O pagamento de juros mais principal é realizado em cascata, ou seja, primeiro é remunerada a classe sênior, depois a mezzanine e, por fim, a classe júnior. Em caso de perdas, entretanto, os impactos serão repassados

\footnotetext{
${ }^{5}$ Segundo Zelman et al. (2007), a participação das hipotecas do tipo Interest Only e Neg-Am no total de hipotecas concedidas em 2006 foi de $23 \%$, um crescimento de 22 p.p. em relação a 2001.
} 
às securities em ordem inversa, a classe sênior seria a última a ter seu pagamento comprometido.

A popularização desses contratos teve duas consequências importantes. Em primeiro lugar, abriu a possibilidade para a criação de operações semelhantes utilizando outros ativos como colateral, principalmente financiamento de automóveis e recebíveis de cartões de crédito, originando os contratos ABS (Asset-Backed Securities) e também os CDO (Collateralized Debt Obligations). Em segundo lugar, integrou definitivamente o sistema de financiamento residencial ao mercado de capitais.

A partir de 2002, a articulação entre as inovações financeiras nos contratos hipotecários e nos processos de securitização possibilitaram a expansão do sistema de financiamento residencial americano em direção a operações associadas a riscos mais elevados. Assim, os segmentos denominados subprime - que reúne tomadores sem histórico de crédito ou com histórico de inadimplência - e Alt-A (Alternative A) - que consistem em empréstimos a tomadores sem comprovação de renda mas com bom histórico de pagamento - apresentaram forte crescimento. De acordo com Zelman et al. (2007), a contratação de hipotecas subprimes saltou de US\$ 213 bilhões em 2002 para US\$ 640 bilhões em 2006.

As operações desse segmento não são elegíveis nem à garantia pública concedida pela FHA nem à securitização pelas GSE por não respeitarem os parâmetros exigidos por essas instituições. Agentes privados, contudo, se responsabilizaram pela transformação dessas carteiras de crédito em títulos, utilizando técnicas complexas de securitização por meio de special purpose vehicles ${ }^{6}$ (SIV).

Os grandes bancos americanos desempenharam um papel importante na construção da pirâmide de crédito que contou com a securitização de hipotecas já securitizadas por meio de collateralized debt obligation (CDO) emitidos por SIV e garantidos pelos bancos através de linhas de crédito ou acordos de recompra (Eichengreen, 2008; Guttmann, 2008).

A composição do pool de ativos ao qual um CDO está vinculado foi realizada de maneira a obter uma melhor classificação de risco, o que não significou a ausência de participação de ativos arriscados. A cooperação entre as agências de rating e os emissores de CDO permitiu que uma classificação AAA fosse obtida atingindo as condições mínimas exigidas para essa nota. Dessa maneira, hipotecas e MBS do segmento subprime foram adicionados ao conjunto de ativos até o limite máximo que garanta a avaliação do CDO desejada pelo emissor. As tranches de maior risco foram adquiridas por agentes especulativos (como os fundos hedge) enquanto as de menor risco foram compradas por fundos de pensão, seguradoras e demais in-

\footnotetext{
${ }^{6}$ Special purpose vehicles consistem em subsidiárias criadas por empresas ou instituições financeiras, sobretudo os grandes bancos que tentam, assim, reduzir o volume de capital exigido pela regulamentação prudencial. Os SIV adquirem os ativos que seus controladores não desejam reter em balanço, financiando a compra por meio da emissão de títulos ou de endividamento bancário de curto prazo. Eichengreen (2008) enfatiza que esses SIV podem se assemelhar aos hedge funds, assumindo graus elevados de alavancagem e descasamentos de prazos.
} 
vestidores institucionais de perfil mais conservador (Mason e Rosner, 2007; Bhatia, 2007).

Apesar de ampliarem a liquidez do sistema de financiamento residencial, as inovações financeiras no mercado secundário de hipotecas tornaram mais complexa a avaliação de risco das operações ao vincularem diferentes segmentos dos mercados de capitais e de crédito. Ademais, incentivaram distorções na estrutura de incentivos ao monitoramento dos riscos (Kregel, 2008). Bhatia (2007) afirma que as novas técnicas de securitização transferiram os riscos dos agentes financeiros mais bem regulados (os grandes bancos, as instituições com seguro de depósito do FDIC, Fannie Mae e Freddie Mac), para as instituições cuja administração de riscos está mais sujeita à disciplina de mercados (hedge funds, fundos de pensão, seguradoras, private equities funds, mutual funds, real estate investment trusts, mortgage companies, sovereing wealth funds etc.) de maneira a ampliar a assimetria de informações, colaborando para ocultar os riscos envolvidos nas operações.

\section{OS DESDOBRAMENTOS DA “CRISE DAS HIPOTECAS SUBPRIME”}

Entre 2001 e 2005, a alta do preço dos imóveis e a expansão do crédito hipotecário assumiram a dinâmica self-reforcing dos ciclos de ativos ${ }^{7}$. A valorização das residências reforçou a solidez patrimonial das famílias, melhorando a avaliação de seus riscos feita pelos credores 8 , e estimulou o aumento do seu endividamento, cujos recursos foram utilizados tanto para a aquisição de novos imóveis, reforçando a alta dos preços desses ativos, como para o consumo, permitindo a recuperação econômica dos EUA após a recessão de 2001 (Cagnin, 2007).

Ao longo desse período a concorrência entre os agentes credores condicionaram a expansão do segmento subprime, especialmente por meio das inovações financeiras associadas a balloon payments. O fim do período de taxas de juros baixas de muito desses contratos ${ }^{9}$ em 2006 e a elevação da taxa de juros básica americana a partir do final de 2004 elevaram o custo financeiro desses créditos, refletindo no nível de inadimplência dessas operações. A ampliação do número de execuções de hipotecas e o endurecimento das condições de crédito determinaram a reversão do ciclo de preço dos imóveis a partir de meados de 2006 (ver Gráfico 3). Com a desvalorização do colateral, foi restringida a possibilidade de refinanciamento das hipotecas dos tomadores em situação patrimonial mais fragilizada (subprime e Alt-

\footnotetext{
${ }^{7}$ Sobre a dinâmica dos ciclos de ativos, ver Aglietta (2008), Belluzzo e Coutinho (1996), Borio e Lowe (2002), Cintra e Cagnin (2007b) e Freitas e Cintra (2008).

${ }^{8}$ A existência de uma garantia real (imóvel) associada ao crédito hipotecário relativiza a importância da análise do fluxo futuro de renda do tomador em favor à expectativa de valorização da garantia (Goodhart e Hofmann, 2007).

${ }^{9} \mathrm{~A}$ taxa de juros durante os dois primeiros anos de existência dos contratos associados a ballon payments era de cerca de $2-3 \%$ a.a. e a partir desse período chegava a $10-15 \%$ a.a.
} 
A), reforçando a tendência de alta da inadimplência (Guttmann, 2008; Freitas e Cintra, 2008).

Devido às interconexões criadas pelas técnicas de securitização, a crise de um segmento relativamente pequeno (apesar do forte crescimento) do sistema de financiamento residencial expandiu-se em efeito cascata para diferentes mercados financeiros ao longo de 2007.

Com os atrasos dos pagamentos das hipotecas subprime, a classificação de risco das MBS que reuniam esses créditos como parte do pool de hipotecas a que estavam referenciadas teve de ser rebaixada pelas agências de rating em 2007. Esse processo de reavaliação pelas agências - que anteriormente haviam classificado esses títulos como de baixo risco - gerou dois efeitos: obrigou que fundos de pensão e seguradoras se desfizessem de suas posições nesses ativos, uma vez que por motivos regulatórios só podem carregar títulos de baixo risco, e, ao gerar desconfiança sobre as avaliações de risco, colocou em questionamento a precificação de todos os MBS não emitidos pelas GSE (Guttmann, 2008; Kregel, 2008).

Gráfico 3: Preço dos imóveis residenciais nos EUA - 1992 a 2008

(variação em relação ao mesmo trimestre do ano anterior)

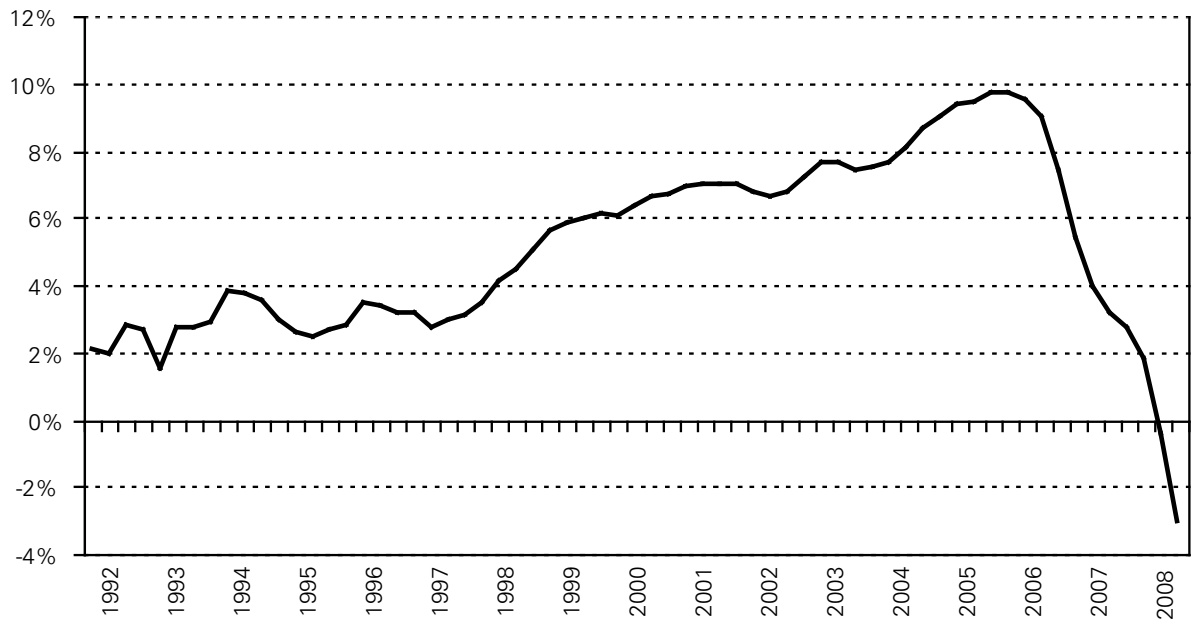

Fonte: Office of Federal Housing Enterprise Oversight (OFHEO.)

Nota: Variação do índice para preço de compra (Purchase-Only Index) com ajuste sazonal.

A desordem instaurada no mercado de MBS se transmitiu para os mercados em que esses títulos funcionavam como garantia. As grandes perdas nos mercados subprime pareciam não ser absorvidas apenas pelos agentes com posições em tranches mais arriscadas dos contratos de collateralizad debt obligations. Dessa maneira os mercados de CDO também passaram por um movimento de revisão e rebaixamento da classificação de risco, acentuando ainda mais o clima de incerteza nos mercados financeiros (Freitas \& Cintra, 2008).

$\mathrm{O}$ mercado de asset-backed commercial paper também foram atingidos pela 
crise. A paralisação desses mercados criou dificuldades para a obtenção de recursos de curto prazo pelos agentes financeiros. A reincorporação dos ativos dos SIV ao balanço dos bancos ocorreu em função da existência de acordos de recompra em caso de desvalorização das carteiras ou então pelo uso crescente das linhas de crédito disponibilizadas por eles (Eichengreen, 2008).

As sucessivas declarações de perdas patrimoniais de grandes bancos nos EUA e na Europa aprofundaram o estado de incerteza nos mercados interbancários. Nessa conjuntura, a incapacidade de estimação dos riscos da contraparte levou ao empoçamento de liquidez nesses mercados, exigindo a intervenção dos bancos centrais. A crise, por diferentes canais construídos pelas inovações financeiras, atingiu assim o mercado interbancário em agosto de 2007.

Diante da gravidade da crise os principais bancos centrais implementaram injeções coordenadas de liquidez e a utilização de novos instrumentos, como o Term Auction Facility e o Term Securities Lending Facility criados pelo Federal Reserve com o objetivo de ampliar a gama de títulos aceitos como garantias nas operações de mercado aberto. A partir de março de 2008, diante da falência do Bear Stearns, o banco central americano criou o Primary Dealer Credit Facility que estendeu o acesso às operações de redesconto (restritas às instituições de depósitos) a outros agentes financeiros e a variedade de títulos dados como garantia (Mishkin, 2008).

Os segmentos mais conservadores do sistema de financiamento imobiliário também foram atingidos. O crescimento da inadimplência das conventional mortgages e o investimento em MBS referenciados a hipotecas subprime e Alt-A impuseram perdas às GSE nos três primeiros trimestres de 2008. Apesar de seus privilégios fiscais e regulatórios, Fannie Mae e Freddie Mac declararam perdas acumuladas no período de US\$ 59,7 bilhões, acima das expectativas dos analistas. Os rumores sobre a solidez das instituições impôs forte queda de seu valor de mercado e ampliou largamente seu custo de captação - os spreads sobre os treasuries saltaram de 0,69 p.p. para 1,39 p.p. entre maio e agosto de 2008 - condicionado em grande medida pela retração da demanda de bancos centrais e sovereign wealth funds asiáticos. $\mathrm{Na}$ tentativa de restabelecer a solidez do sistema e impedir um racionamento mais profundo do crédito imobiliário, o governo americano adotou um conjunto de medidas por meio do Housing and Economic Recovery Act de 2008.

Entre as principais ações, destaca-se a criação da Federal Housing Finance Agency (FHFA), uma agência reguladora para as GSE (Fannie Mae, Freddie Mac e os FHLBanks), centralizando as operações antes dispersas em três outras instituições (Federal Housing Enterprise Oversight - OFHEO, Federal Housing Finance Board - FHFB e parte das atividades do Department of Housing and Urban Development - HUD). A nova agência apresenta uma ampliação de poderes, podendo estabelecer exigências mais elevadas de capital e possuindo autoridade sobre o tamanho e as características do portfólio das GSE.

Diante da deterioração da situação patrimonial da Fannie Mae e da Freddie Mac, o governo americano decidiu assumir, no dia 6 de setembro de 2008, a gestão dessas entidades por meio da intervenção (conservatorship) da FHFA, seguido da substituição de suas diretorias. Juntamente com o Tesouro e o Federal Reserve, a 
FHFA busca restabelecer a saúde financeira dessas duas GSE e a normalidade das operações de securitização de hipotecas, sobretudo para os segmentos de menor risco (prime). A injeção de capital do Tesouro por meio do Senior Preferred Stock Purchase Agreement somou US\$ 100 bilhões em cada uma das GSE em troca de ações preferenciais. Ademais, o governo americano criou linhas temporárias de crédito de curto prazo para essas entidades, tomando como garantia MBS e advances $^{10}$. Por meio do MBS Purchase Program, por sua vez, o Tesouro passou a ser capaz de comprar diretamente as MBS emitidas pela Fannie Mae e Freddie Mac. O Federal Reserve também anunciou suporte aos títulos de dívida emitidos por essas suas entidades e pelos FHLBanks, somando recursos de US\$ 100 bilhões, além de outros US\$ 500 bilhões que serão dirigidos para a compra de MBS (Bernanke, 2008b; FHFA, 2008).

De forma geral, o sentido das medidas adotadas até o início de 2009 é de reafirmar o modelo atual de financiamento residencial americano e de impedir os "excessos" cometidos nos últimos anos, daí a criação de uma nova agência reguladora. Algumas de suas principais características são conservadas: os estreitos laços com os mercados de capitais e a centralidade das operações de securitização para o funcionamento do sistema. Após dezembro de 2009, contudo, quando expiram a maior parte das medidas adotadas, a questão do papel do governo na gestão das GSE deve ocupar o centro do debate. Ainda que seja possível a privatização ou a estatização definitiva dessas entidades, o caminho mais provável é que a ambiguidade do papel do setor público seja reduzida, definindo-se critérios e instrumentos para futuras intervenções. De qualquer forma, como aponta Bernanke (2008a), o suporte do Estado mostrou-se importante para que a crise desse sistema de financiamento não fosse ainda mais profunda:

"Fannie Mae and Freddie Mac continued to produce and sell significant quantities of mortgage-backed securities to secondary-market investors throughout the period of turmoil. Their ability to continue to securitize when private firms could not did not appear to result from superior business models or management. Instead, investors remained willing to accept GSE mortgage-backed securities because they continued to believe that the government stood behind them. That experience suggests that, at least under the most stressed conditions, some form of government backstop may be necessary to ensure continued securitization of mortgages".

\section{CONCLUSÃO}

O sistema americano de financiamento residencial passou por profundas transformações institucionais entre os anos 1960 e 1980 cujos desdobramentos consistiram na elevação da concorrência nesse segmento do mercado de crédito e no es-

\footnotetext{
${ }^{10}$ Nome dados aos empréstimos realizados pelos 12 Federal Home Loan Banks aos seus bancos associados.
} 
treitamento dos seus vínculos com os mercados securitizados, ampliando a capacidade de introdução de inovações financeiras tanto nos contratos firmados junto às famílias como nas operações de securitização das carteiras de crédito hipotecário. A ampliação da securitização dessas carteiras, ao distorcer a estrutura de incentivos de uma avaliação criteriosa dos riscos, permitiu que as instituições credoras, diante dos imperativos da concorrência, introduzissem inovações financeiras cada vez mais complexas de maneira a atender a demanda dos tomadores de maior risco.

A partir de 2001, num ambiente de baixas taxas de juros e de valorização dos imóveis residenciais, as instituições financeiras atuantes nesse segmento do mercado de crédito se lançaram na conquista de novos clientes. Nesse processo, à medida que a parcela do mercado composta por tomadores de menor risco se saturava, a introdução de inovações cumpria seu papel de maneira a adequar as condições de oferta e de demanda de crédito. A busca por níveis mais elevados de rentabilidade nos mercados securitizados possibilitou a expansão das operações de securitização desses contratos "exóticos", realizada principalmente por instituições privadas sem qualquer tipo de garantia pública.

A difusão de novas práticas de securitização criou vínculos entre diferentes segmentos dos mercados financeiros que foram responsáveis pela transmissão das perdas no momento da elevação da inadimplência das hipotecas subprime. $\mathrm{O}$ ambiente de incerteza daí resultante levou ao rápido aprofundamento da crise. Apesar da magnitude da desvalorização da riqueza financeira e imobiliária e dos impactos negativos sobre o crescimento econômico dos EUA e dos principais países desenvolvidos, a crise originada no segmento subprime das hipotecas americanas não parece ter desencadeado nenhum processo radical de transformação da atual arquitetura financeira, como ilustra a reforma do sistema de financiamento residencial implementada até 2009.

\section{REFERÊNCIAS BIBLIOGRÁFICAS}

AGLIETTA M. (1987) Structures économiques et innovations financières. Revue d'Economie Financière, p. 43-58, n. 2.

AGLIETTA, M. (2008) Macroéconomie financière. Paris : La Découverte.

AMABLE, B. (2005). Les cinq capitalismes. Paris : Seuil.

BELLUZZO, L. G. \& COUTINHO, L. (1996) "Financeirização" da riqueza, inflação de ativos e decisões de gasto em economias abertas. Economia e Sociedade, pp. 137-150, n. 11.

BERNANKE, B. S (2007) Housing, Housing Finance and Monetary Policy. Federal Reserve Bank of Kansas City's Economic Symposium, ago. Disponível em http://www.federalreserve.gov/.

BHATIA, A. V. (2007) New Landscape, New Challenges: structural change and regulation in the U.S. financial sector. IMF Working Paper, ago. Disponível em http://www.imf.org/

BORIO, C. \& LOWE, P. (2002) Asset prices, financial and monetary stability: exploring the nexus. Basle: BIS working papers, n. 114. Disponível em http://www.bis.org/.

CAGNIN, R. F. (2007) O mercado imobiliário e a recuperação americana após 2002. Campinas: Dissertação de Mestrado, Instituto de Economia da Universidade Estadual de Campinas.

CINTRA, M. A. M. (1997) As transformações na estrutura do sistema financeiro dos EUA: a monta- 
gem de um novo regime monetário-financeiro (1980-1995). Campinas: Tese de Doutoramento, Instituto de Economia da Universidade Estadual de Campinas.

CINTRA, M. A. M. \& FREITAS, M. C. P. (org.) (1998) Transformações institucionais dos sistemas financeiros: um estudo comparado. São Paulo: FAPESP e Fundap.

CINTRA, M. A. M. \& CAGNIN, R. F. (2007a) Evolução da estrutura e da dinâmica das finanças norte-americanas. Econômica, pp. 89-131, n. 9(1).

CINTRA, M. A. M. \& CAGNIN, R. F. (2007b) Euforia e pessimismo: os ciclos de ativos, de crédito e de investimento da economia americana, após 1982. Novos Estudos, CEBRAP, pp. 23-44, n. $79(1)$.

COLTON, K. W. (2002) Housing finance in the United States: the transformation of the U.S. housing finance system. Joint Center for Housing Studies, Harvard University. Disponível em http://www. jchs.harvard.edu.

DODD, R. (2007) Subprime: tentacles on a crisis. International Monetary Fund, Finance \& Development. Disponível em http://www.imf.org/.

ECONOMIST (The) (2008) Still Bleeding : Fannie, Freddie and Lehman ensure August is anything but quiet. The Economist print edition.

EICHENGREEN, B. (2008) Dix questions à propos de la crise de prêts subprime. Banque de France, Révue de la stabilité financière, pp. 19-29, n. 11, fev.

FREITAS, M. C. P. (1997) A Natureza Particular da Concorrência Bancária e seus Efeitos sobre a Instabilidade Financeira. Economia e Sociedade, pp. 51-83, n. 8(1).

FREITAS, M. C. P. de \& CINTRA, M. A. M. (2008) Inflação e deflação de ativos a partir do mercado imobiliário americano, Revista de Economia Política, pp.414-433, vol. 28, n. 3 (111).

GOODHART, C. \& HOFMANN, B. (2007) House prices and the macroeconomy. New York: Ed. Oxford.

KREGEL, J. (2008) Minsky's cushions of safety: systemic risk and the crisis in the U.S. subprime mortgage market. Public Policy Brief No. 93, The Levy Economics Institute of Bard College. Disponível em http://www.levy.org/vdoc.aspx? docid=974.

MASON, J. \& ROSNER, J. (2007) Where did the risk go? How misapplied bond rating cause mortgage backed securities and collateralized debt obligation market disruption”. Hudson Institute. Disponível em http://hudson.org/files/publications/Hudson_Mortgage_Paper5_3_07.pdf

MINSKY, H. P. (1984) Financial Innovations and financial instability: observation and theory. In Financial innovations: their impact on monetary policy and financial markets, p. 21-41. The Federal Reserve Bank of St. Louis, Kluwer-Mighoff, Boston.

MINSKY, H. P. (1986) Stabilizing an unstable economy. New Haven: Yale University Press.

MISHKIN, F. S. (2008) Global Financial Turmoil and the World Economy. Speech at the Caesarea Forum of the Israel Democracy Institute, Israel. Disponível em http://www.federalreserve.gov

OFFICE OF FEDERAL HOUSING ENTERPRISE OVERSIGHT (2003). Systemic risk: Fannie Mae, Freddie Mac and the role of OFHEO. Disponível em http://www.ofheo.gov/Media/Archive/docs/ reports/sysrisk.pdf .

U.S. DEPARTMENT OF HOUSING AND URBAN DEVELOPMENT - HUD (2006). Evolution of the U.S. housing finance system: a historical survey and lessons for emerging mortgage markets. Disponível em: http://www.huduser.org/publications/hsgfin/US_evolution.html .

VALLEE, D. E. (2006). A new plateau for the U.S. securitization market. Federal Deposit Insurance Corporation Outlook. Disponível em http://www.fdic.gov/bank/analytical/regional/ro20063q/na/ t3q2006.pdf.

ZELMAN, I.; McGILL, D.; SPEER, J. \& RATNER, A. (2007). Mortgage liquidity du jour: underestimated no more. Sector Review, Credit Suisse. Disponível em http://billcara.com/CS\%20Mar\%2 012\%202007\%20Mortgage $\% 20$ and $\% 20$ Housing.pdf. 